\title{
Impacts of Prolonged Waterlogging on Educational Continuity at Schools in Peri-Urban Areas of Dhaka, Bangladesh
}

\author{
Md. Humayun Kabiri ${ }^{1}$, Iftekhar Ahmed ${ }^{2}$, Jason von Meding 3 , Giuseppe Forino ${ }^{4}$ \\ and Amit Kumar Ghosh ${ }^{1}$
}

\author{
${ }^{1}$ Department of Geography and Environment, University of Dhaka, Dhaka 1000, Bangladesh \\ ${ }^{2}$ School of Architecture and Built Environment, University of New Castle, Australia \\ ${ }^{3}$ Florida Institute for Built Environment Resilience, University of Florida, United States of America \\ ${ }^{4}$ University of East Anglia, School of Environmental Sciences, United Kingdom \\ Manuscript received: 15 December 2020; accepted for publication: 12 February 2021
}

\begin{abstract}
The purpose of the paper is to explore the massive impediments and challenges to continuing school education posed to school stakeholders due to protracted waterlogging in the peri-urban areas of Dhaka, Bangladesh. The primary data were collected through direct field observation, in-depth interviews, Focus Group Discussions (FGDs) and Key Informant Interviews in three academic institutions (primary school, high school, and higher secondary school/college) located in different peri-urban areas of Dhaka City. The research revealed that students, teachers, and families experience severe problems due to waterlogging every year. Academic activities are significantly interrupted and discontinued for long spells almost every year. In addition, students suffer from different types of diseases such as cold and fever, and water-borne and skin diseases. Books, clothes, and other belongings of students are often badly damaged. Ensuring Comprehensive School Safety (CSS), maintaining proper drainage system in and around the schools, and raising playgrounds, roads and plinths of buildings are some of the key steps that can contribute to better educational continuity in Dhaka's schools.
\end{abstract}

Keywords: Waterlogging, Educational continuity, Schools, Peri-urban areas, Dhaka

\section{BACKGROUND}

Bangladesh with an area of around $148,000 \mathrm{~km}^{2}$ is currently hosting over 160 million people and ranks fifth in the top fifteen countries on earth with highest disaster risk (Rahman et al. 2016; Shaw et al. 2013). Around $30 \%$ of the people live in urban areas with at least $40 \%$ of the total people living in dismal conditions. Dhaka, the capital city of the country hosts the largest concentration of people (18 million people) largely due to rural to urban migration. The city's density is more than 40,000 persons $/ \mathrm{km}^{2}$ and has experienced phenomenal growth in the last few decades (Dewan and Corner, 2014). With its growth both in terms of population and area, it experiences various environmental issues including severe air, water, land and noise pollution and mismanagement of waste, posing critical hazards to the city dwellers (Dewan et al. 2012). Poor urban planning, excessive population density and a population of over four million in

Corresponding author: Humayun Kabir

Email: mhk.geoenv@du.ac.bd

DOI: https://doi.org/10.3329/dujees.v9i1.54857 informal settlements, have exacerbated the conditions.

Due to rapid unplanned and unregulated urban expansion, Dhaka suffers from the problems of drainage and stagnation of rainwater, leading to flooding and waterlogging during the monsoon season. Before the construction of protection embankments, the city experienced destructive flooding events in 1987, 1988, 1998 and 2004 mainly due to excessive rainfall (ADB and WB, 2005; Dewan et al., 2007), and such events continue to occur. The duration of floods in 1988 and 1998 was more than two months, when school education was severely affected. In many cases, the schools were used as flood shelters. In the 1998 flood, nearly 300 relief camps were set up in Dhaka City, most of which were established in educational buildings especially schools (Alam et al. 2011; Islam, 2005; Ahmad, et al. 2000). After these two massive flooding events, protection embankments were constructed in the western and eastern parts of the city. Nonetheless, severe waterlogging occurs regularly in many parts of the city, affecting school education. Currently excessive rainfall induced water gets trapped due to lack of 
adequate drainage in densely built areas resulting in waterlogging, a specific form of urban disaster.

Moreover, the city faces other risks including earthquakes, heat waves and fires (Ahmed, 2014). These hazards are gaining strength due to lack of adequate infrastructure, overcrowding, high-density construction, unsafe and inadequate housing, poor healthcare and limited basic services. A significant part of Dhaka's population lives in unsafe and abject housing conditions in the per-urban areas and are often deprived of adequate amenities and facilities. In many cases, industries (chemical, re-rolling, tanneries, etc.) are located in these areas. During the wet season, due to excessive rainfall these areas often get inundated and the educational institutions remain under water for weeks. Chemical effluents disposed from industries, mix with storm water, which remains stagnant for days in school compounds. Children's health is at serious risk due to exposure to chemicals from the nearby industries, and at the same time, their academic activities are greatly disrupted due to waterlogging. Stagnation of water prevents schools from continuing uninterruptedly, and students experience severe difficulties of attending school in waterlogged conditions.

Based on this background, this paper aims to understand the sufferings and difficulties of different school stakeholders (students, teachers, guardians, school management committees and the administrative authority) face due to waterlogging, and thereby suggest policy and practice guidelines for effective educational continuity. The paper draws from a larger study funded by Save the Children that aimed at exploring challenges and opportunities for educational continuity after floods in urban areas of South and Southeast Asia (von Meding et al. 2018).

Key research objectives are:

- To identify the impacts of prolonged waterlogging on school stakeholders both in long and short terms.

- To evaluate the critical factors enabling and blocking educational continuity following floods in Dhaka.

- To suggest some practical ways for the variety of school stakeholders so that they can minimize disruption to education in the flooding events.

\section{EDUCATIONAL CONTINUITY IN BANGLADESH}

The education system in Bangladesh is divided into three main stages: pre-primary/primary, secondary and tertiary. Pre-primary and primary education last one year and takes place prior to entry into the primary school while primary education lasts for five years and is both free and compulsory for children aged 6-10 years (grades 1-5). Secondary education: lasts seven years (grades 6-12) and is further sub-divided into three sub-stages: 3 years of junior secondary; two years of secondary and two years of higher secondary; iii) tertiary education: (18+ years) ranges from 3-5 years and is provided by universities (Ministry of Education, 2010). There are different types of primary schools: government, registered NGO schools, community schools, high school attached primary sections, and private schools. Like the pre-school systems, only the private primary schools charge a tuition fee, while the government provides students with a set of free textbooks to all other schools. At the secondary level, the government subsidizes the textbooks and tuition fees.

According to the Bureau of Education Information and Statistics (BANBEIS), there are 113,823 primary and post-primary education institutions across Bangladesh. Within this category there are 78,685 primary institutions, 19,070 school level institutions, 3,475 college level institutions, 9,330 madrasa (religious schools) institutions, 282 professional institutions, and 2,981 technical-vocational education institutions (BANBEIS, 2016). There is a total of 849,304 teachers of which over $41 \%$ teach at the primary level across both private and public institutions. Nearly $50 \%$ of the teachers at the primary level are women. In 2011, just over 30 million children were enrolled within the formal education system, with the majority attended public institutions at the primary school level, with 9,904,254 attending public schools and 7,053,640 attending private schools. There is a substantial shift at the school education level (grades 6-10) where just 228,242 attend public institutions and 7,281,976 attend private institutions. According to BANBEIS the net enrollment rate for primary school students (grades 15) was $94.89 \%$ (a total of $15,751,788$ children) and the average dropout rate was $45.1 \%$ (2010), perhaps due in part to the regular impacts of disasters such as 
floods. In low-income households, children are drawn into work, a factor behind the high dropout rate.

\section{Urban Disasters and Impacts on Schools}

Disasters impact the education sector extensively in Bangladesh with an estimated 5,000 schools being affected annually, and more of them by flooding than other disasters (Alam et al., 2011). As discussed earlier, the academic activities in schools of urban areas particularly in the large cities (for example, Dhaka) are interrupted due to excessive downpour induced waterlogging every year. Moreover, these schools are also vulnerable to earthquake and fire hazards. Over 300 schools in Dhaka were used as flood shelters in the 1998 flood (Alam et al. 2011; Islam, 2005; Ahsan and Khatun, 2004). The urban waterlogging problem is frequent and common in Dhaka in the wet months, which particularly impacts the city's poor (Parvin et al. 2013). Prolonged waterlogging affects schools in Dhaka by complete or partial inundation.

\section{School Education and DRR Approaches in Bangladesh}

Bangladesh being a disaster-prone country is at risk to natural and man-made hazards. Educational institutions are serious sufferers in these events. Flooding is the most frequent hazard resulting in heavy economic tolls on people and the national economy. Between 1972 and 2009 the country faced 10 major floods. From 2000-2010 a total of 50,000 educational institutions were either damaged or destroyed by floods whereas in 2007, 13,000 educational institutions were either fully or partially damaged by the flood (UNICEF, 2010). The super cyclone of 1970 killed 300,000 people and over 4,000 schools were damaged. In April 1991, one of the deadliest tropical storms ever recorded killed 140,000 people and 9,300 schools were destroyed. Moreover, floods of 1998 and 2004 were most catastrophic than the other disasters; in total over 13,718 and 17,853 schools were affected partially or fully damaged (ECHO, 2010).The 2007 Sidr cyclone and associated floods caused around 4,000 deaths and a total of 13,362 schools were fully or partially affected. In 2009, as a result of cyclone Aila around 5,000 educational institutions were damaged. In 2007 as a result of a cyclone and floods, nearly $95 \%$ of schools experienced some level of impact and around $84 \%$ of schools were closed for an average of 26 days; about
$65 \%$ of schools were used as shelters for cyclone affected people and $35 \%$ of schools were used to accommodate community members that were affected by the floods. This alternative use of schools resulted in a 3\% school drop-out (Save the Children, 2017; Alam et al. 2011). Floods continue to occur regularly and impact education; disruption in the continuity of school education in Bangladesh has been reported in the recent massive floods of 2017 (particularly in the northeastern part of the country) and 2018 (NIRAPAD, 2017; ACAPS, 2017).

Initially, the priority of disaster management activities was more response oriented, but gradually shifted to a risk reduction oriented approach particularly after 2000. The National Plan for Disaster Management 2016-2020 (MoDMR, 2016) recognizes the importance of school safety with a focus on developing and implementing a school safety program including national school safety and school buildinglevel emergency response plans. The national education policy emphasizes on initiating special measures to promote education in the areas identified as backward in education (MoE, 2010).The Standing Orders on Disaster (SOD) (MoDMR, 2019) prepared originally in 1997 and updated in 2019 guides and monitors disaster management activities including in the government schools. It has provided clarity and guidance around how other ministries should collaborate and coordinate on disaster risk reduction initiatives across the education sector. Risk reduction mechanisms are also initiated within the government to support risk reduction activities in the education sector. Launched in 2010, the National Education Policy seeks to build students' knowledge, social awareness, and capacities with regard to issues in their environment and help build the nation's resilience against climate change and disasters. The National Children Policy 2012 dedicates a section on child protection during and after a disaster. Three primary ministries and their respective directorates and departments are involved in risk reduction within the education sector: The Ministry of Education (MoE), the Ministry of Primary and Mass Education (MoPME) and the Ministry of Disaster Management and Relief (MoDMR).The MoE through the National Curriculum and Textbook Board (NCTB) has incorporated disaster management issues into the primary and secondary curricula for grades 3-11. School disaster risk reduction interventions include 
earthquake vulnerability assessment of school buildings, preparing evacuation plans, training of teachers on earthquake safety measures, and evacuation and classroom lectures on earthquake safety and preparedness for school children. Under the Memorandum of Understanding between the MoE and Comprehensive Disaster Management Program (CDMP II), the Directorate of Secondary and Higher Secondary Education reported activities to make schools safe from disasters, although these initiatives are yet to be widely implemented.

\section{Comprehensive School Safety Measures in Bangladesh}

In Bangladesh, DRR and Climate Change Adaptation (CCA) have been incorporated into some thirty-nine textbooks since 2005 through the NCTB. In 2014, the MoE with financial and technical support from CDMP, further integrated disaster preparedness in ten textbooks. NCTB has introduced disaster and climate change-related chapters within the textbooks, for instance in the General Science and Social Sciences subject areas that cut across the three levels of primary school (grades 1-5), junior high school (grades 6-8) and secondary high school (grades 9-10). Some DRR topics are also integrated in Religion and Moral Studies, Bengali, English, Bangladesh and Global Studies, English Literature, Bengali, and Geography subjects at various grade levels. The latest development, however, is the adoption of the Framework for DRR in Education and Education in Emergencies in schools, which is now under the process of review and approval by the MoE (Lim et al. undated). The framework is to guide mainstreaming Comprehensive School Safety (CSS) in the country's education sector. The Framework is inclusive and based on the three pillars of the global CSSF (Comprehensive School Safety Framework): i) Safe School Facilities, ii) School Disaster Management (SDM) and Educational Continuity, and iii) ClimateSmart Disaster Risk Reduction Education (GADRRRES, 2017). The main steps of the CSS are intended to provide national guideline for assessing the structural integrity of school facilities, and for construction and retrofitting of schools.

\section{RESEARCH DESIGN}

The study concentrated on three peri-urban areas (Shayampur, Jatrabari and Madartek) of Dhaka, was carried out during 2017-2018. Three different schools (primary, secondary and a higher secondary) from these areas were purposively selected since these institutions experience waterlogging every year during the monsoons (Figure 1). Brahmanchiran Sishukallayan Primary School (grades 1-5) of Jatrabari, Backchar High School (grades 6-10) of Shayampur and Madartek Abdul Aziz Higher Secondary School (grades 11-12) were selected for the study. It is important to note that in Bangladesh, secondary schools (grades 6-10) are known as high schools and higher secondary school level includes grades 11-12. The study team selected the schools after undertaking reconnaissance survey to assess their vulnerability to waterlogging and/or flooding. As mentioned, five key stakeholders associated with schools were considered for interviews and focus group discussions (FGDs). The stakeholders include students of various levels (grades 1-12), teachers, parents, school management/governing body members and administration (Ministry of Education, and Primary and Mass Education Directorate) (Table 1 and Table 2).

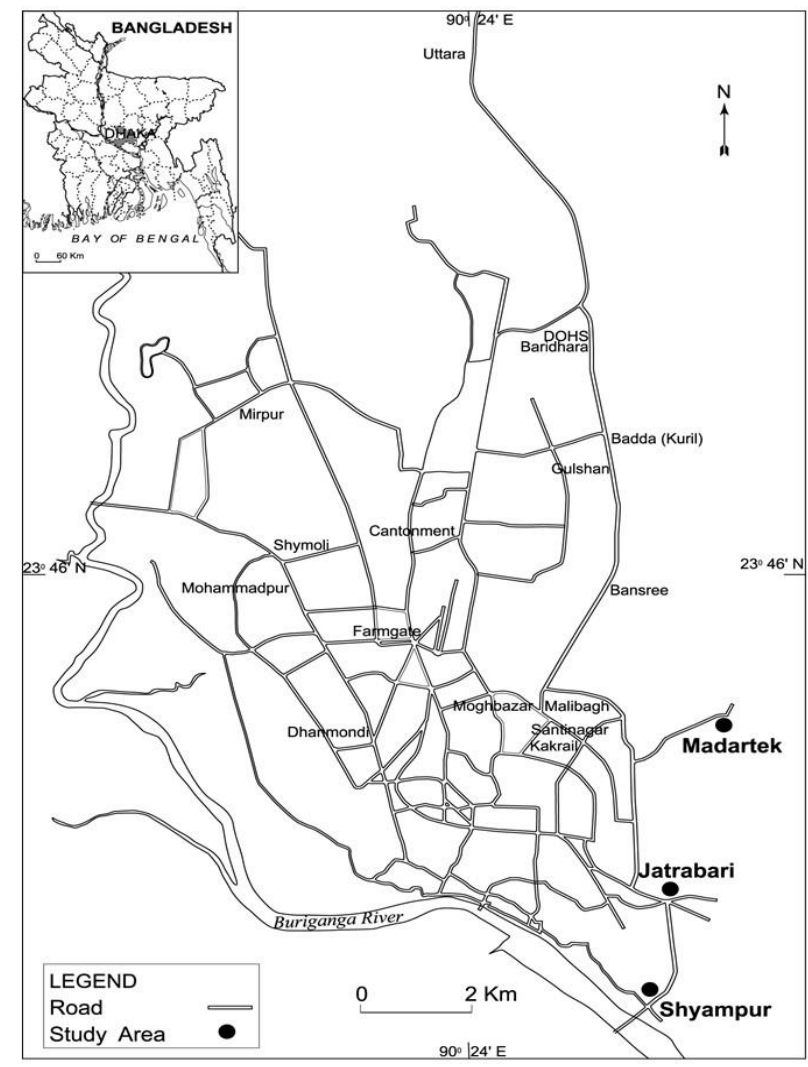

Figure 1: Location of the Study Schools in Dhaka Source: GIS Lab, Department of Geography \& Environment, DU 2017 
A total of 32 individual interviews and 18 Focus Group Discussions (FGDs) were conducted from three academic institutions. In addition, 5 Key Informant Interviews (KIIs) were also conducted. The following tables show the distribution of respondents for the study.

Table 1: Phase I (Individual Interviews=32)

\begin{tabular}{|l|c|c|c|c|}
\hline Stakeholders & Primary & Secondary & $\begin{array}{c}\text { Higher } \\
\text { Secondary }\end{array}$ & Total \\
\hline Students & 3 & 3 & 3 & 9 \\
\hline Teachers & 3 & 3 & 3 & 9 \\
\hline Parents & 3 & 3 & 3 & 9 \\
\hline $\begin{array}{l}\text { Management } \\
\text { Committee } \\
\text { Members }\end{array}$ & 1 & 1 & 1 & 1 \\
\hline $\begin{array}{l}\text { Education } \\
\text { Ministry/ } \\
\text { Directorate }\end{array}$ & - & - & - & 2 \\
\hline Total & 10 & 10 & 10 & 32 \\
\hline
\end{tabular}

Table 2: Phase II (Focus Group Discussions=18)

\begin{tabular}{|l|c|c|c|c|}
\hline Stakeholders & Primary & Secondary & $\begin{array}{c}\text { Higher } \\
\text { Secondary }\end{array}$ & Total \\
\hline Students & 2 & 2 & 2 & 6 \\
\hline Teachers & 2 & 2 & 2 & 6 \\
\hline Parents & 2 & 2 & 2 & 6 \\
\hline Total & 6 & 6 & 6 & 18 \\
\hline
\end{tabular}

The selection of student respondents for individual interviews from different schools was made based on the age of students. Students below 10 years of age were not considered for interviews. For the primary school, student of grades 4 and 5 were considered for interviews. In case of the FGD group selection from the primary school, at least one of guardians of grade 5 students was ensured. In addition to the primary data collected from the schools, a number of institutions (Save the Children, Ministry of Education, Ministry of Primary and Mass Education, etc.) and relevant reports have been consulted.

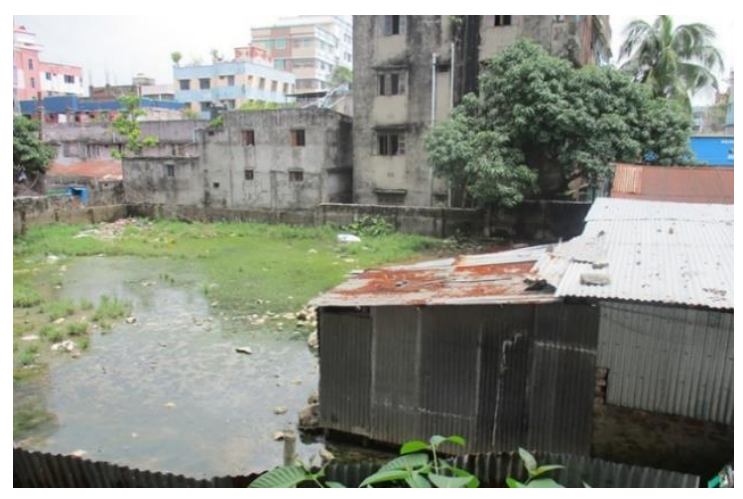

Figure 2: Densely Built Peri-urban Areas of Dhaka Experience Regular and Prolonged Waterlogging.

Source: Iftekhar Ahmed, 2017

The data collected from interviews and FGDs was subjected to thematic analysis that involved a manual coding method to identify key themes. A six-step process commonly used in thematic analysis was followed, including familiarisation, coding, generating themes, reviewing themes, defining, and naming themes and writing up (Braun and Clarke, 2019; Caulfield, 2019). The interview and FGD responses were analysed through the coding process according to different stakeholder groups to gain an insight into the main problems for educational continuity posed by flooding and waterlogging and to identify possible ways to address them. The thematic codes consisted mainly of perspectives of the respondents regarding the challenges and measures to overcome them, and then earmarking recurrent and also unique themes to inform the recommendations.

\section{IMPACTS OF WATERLOGGING ON SCHOOLS IN DHAKA: STAKEHOLDERS PERSPECTIVES}

In this study, as mentioned earlier, five stakeholders across three different schools (primary, secondary, and higher secondary) in Dhaka City were consulted to evaluate their experiences of waterlogging conditions. In the school community, stakeholders are not equally affected by regular floods. In fact, students and parents/guardians encounter the most challenges. Flooding disrupts students' school activities, while prolonged exposure to contaminated and stagnant water in school buildings leads to illness. Families suffer as they are forced to adapt their everyday life to the disruptions in their children's school schedule. Teachers are also affected as they are required to be present at work despite waterlogged conditions in the school and flooding impacts on their families and homes. The following section presents the specific challenges of flooding faced by the various school stakeholders as they expressed during the interview process and focus group discussions.

\section{Students' Perspectives}

The issues of waterlogging are perceived in various ways by the students of the case study schools in Dhaka. Most of them mentioned that water entering 
the school building and classrooms hampers continuity of education. Local roads get damaged due to prolonged water stagnation. Students face difficulties in walking to the school building. Classrooms, school building structure and furniture get damaged and playgrounds cannot be used for the entire wet season. Female students face more difficulty than males because of local clothing practices that require woman and girls to dress in longer, modest, clothing. As a result, the students' uniforms are more likely to get wet as they drag on the ground, increasing their risk of water borne diseases such as diarrhea and skin infection. Students face breathing problems in a highly contaminated environment and experience scarcity of pure drinking water at school. Students also feel psychologically weakened. Accidents in waterlogged condition are common. Moreover, during water stagnation, classes and exams often get postponed and students' families move away elsewhere to relatives' houses if their houses are also flooded. A female student of grade eight at Backchar High School of Shayampur shared her difficulties in the waterlogged condition when going to school - "Our school gets waterlogged every monsoon. The entire path to school from my home gets waterlogged. I walk through the black colored water contaminated by chemicals from nearby industries. This is how I come to my classes with tremendous suffering".

\section{Guardians' Perspectives}

Most guardians mentioned that flooding disrupts students' academic activities, particularly when students' equipment (books and uniforms) get wet as they are unable to complete their work. Often times, many guardians are forced to purchase new equipment to replace those damaged by water. However, due to financial constraints caused by the flooding, many guardians cannot afford to buy new books and clothes for their children. Due to the waterlogged condition of their schools and the dangers of travel, children are often reluctant to attend school and prefer to stay at home. However, they are still exposed to contaminated water leading to diseases like asthma, skin infections, fever, and diarrhea, which are expensive ailments to treat. The treatment cost of skin diseases is high and difficult to afford. As flooding conditions worsen, parents and guardians become uneasy as their children attempt to commute to class.

Interview results with guardians also show that in addition to diseases, they also face difficulties in repurchasing children's books that become damaged due to heavy rain and waterlogging. Waterlogged streets pose multiple threats to pedestrians especially as drain and manhole covers are dislodged leaving open cavities in the ground. Broken shards of glass and other debris are also found in these waters. Furthermore, stagnant water attracts insects such as mosquitoes that transmit harmful diseases. If students are infected, they are advised to refrain from attending class which may disrupt their educational experience for long periods of time. Because of the numerous potential threats posed to students during flood events parents remain in a perpetual state of concern for the safety and well-being of their children.

Results from FGDs with students show that they face difficulties not only while coming to school in waterlogged condition, but also staying at home as their homes get waterlogged very often. A guardian of a male student of class five at Brahmanchiran Sishukallayan Primary School of Jatrabari described "We live in a house that gets flooded as does the school. We face many difficulties in the waterlogged condition. We do not feel safe sending our son to school. I have to buy his books several times. He suffers from fever with cough. His education is highly disturbed".

Transportation also becomes a challenge for students as water stagnation damages local roads resulting in difficulties commuting to and from school. Furthermore, automotive accidents are more likely to occur in flood events. Flooding leads to the inundation of playground areas which cannot be used for the remainder of the wet season or until water levels drop. When the flood has subsided, playgrounds become muddy and slippery while unpleasant smells persists throughout the school compounds. Waterlogged conditions ultimately result in students' poor performance, beyond the control of their guardians.

\section{Teachers' Perspectives}

Teachers of the schools are also the victims during waterlogging as they are bound to attend the schools. During big flooding events, the school is used as a flood shelter and the schools remain closed. The furniture, walls, and floors of schools get damaged and syllabuses are not completed on time. So, cancellation of classes and poor attendance hamper the academic schedule. In waterlogged situations, 
students are reluctant to attend classes; there is always the risk of accidents in waterlogged places. Teachers are required to run classes despite the waterlogging situation. They still remember the past flooding events and sufferings. In the 2004 flood, some schools were closed for 15-20 days. A water purification system is not available, and it becomes unhealthy staying in the damp classrooms. Most of the teachers also mentioned that they pay for rickshaws to transport them to work during waterlogged conditions.

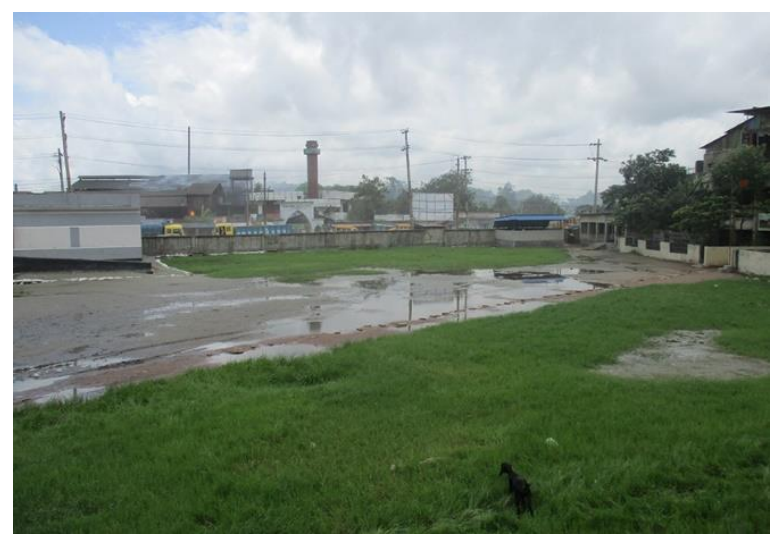

Figure 3: Waterlogging in a Case study school's compound Source: Iftekhar Ahmed, 2017

A female teacher of Backchar High School of Shayampur shared her sufferings in the waterlogged condition- "We have to come to school every day even if it rains. We face a lot of problems while coming to school, do not get transport, especially rickshaws are not available on rainy days and rickshaw drivers do not want to come through the waterlogged situation. At school, we inhale toxic gases throughout the year. How can we ensure good teaching in such an environment?"

\section{School Management Committees and Education Administrators' Perspectives}

School management committees have expressed concern as stagnant floodwater in and around school property disrupts the continuity of education resulting in a decrease in student attendance. In their opinion, as playground areas flood, students are less likely to leave the comfort and safety of their homes. Furthermore, the presence of adjacent industrial areas poses health hazards as they emit harmful chemical smoke. Student attendance is hampered further as it becomes difficult for female students to come to school due to the risk of saturating their longer, draping, uniforms in unsanitary floodwater. To overcome the education gap, ensuring the ability of teachers to work is another challenge for school committees.

During flood events, scarcity of drinking water arises and water-borne diseases become common, especially diarrhea, fever, cough, and skin irritations. Perpetuating this issue is the fact that schools receive negligible allocation from authorities for pure drinking water. Educational authorities perceive that flooding in Dhaka severely hampers the continuity of school education. During flood events, the schools are often used as shelters and on some occasions, remain completely closed. Authorities have also stated that flooding disrupts the education system, particularly in the peri-urban areas, as student curricula cannot be completed as scheduled. Various programs instituted in attempt to remedy the situation have proven to be insufficient.

\section{MEASURES ADOPTED IN WATERLOGGED CONDITIONS}

During flood events, school stakeholders in Dhaka adopt various strategies to cope with the interruption of academic activities. Many students complete additional take-home assignments to make up for lost work and some elect to take private tuition or seek help from fellow classmates. Students keep in contact with others through mobile phones or social media to stay informed on class updates and schedule changes. Many students have learned methods for water purification and received training from the NGO, Plan International, on proper waste disposal, drain cleaning, installation of public toilets and how to raise public awareness on the effects and remediation of earthquakes, flooding and other hazards.

Whenever possible, parents transport their children to school during flood events and homeschool their children when schools are closed. They advise their children to remain indoors during flooding, to avoid outdoor hazards, and communicate with the school authority to stay informed on any updates regarding class schedule changes. Parents advise their children on the importance of maintaining proper hygiene to decrease their risk of contracting water-borne illnesses and irritations. Some parents received local municipal member's suggestions on how to respond during and before floods and how to manage their household waste. 
While attempting to support the families connected to each school, teachers and faculty often face many operational challenges introduced by flooding. Many teachers attempt to assist students in draining/removing debris from their playground areas and, in some cases, fill low areas with sand. They often work to quickly drain water from the schools through strategic sand-bag placement and advise students to sleep with mosquito nets, drink clean boiled water, and keep food covered. They encourage students to finish their schoolwork at home and seek aid if they face any difficulties in understanding their work. Extra classes are hosted regularly, and students are advised to prioritize safety during flood events. Teachers often keep in contact with the parents and guardians of their students, through mobile phones, to keep them informed of any schedule changes and attempt to provide clean drinking water if possible. Furthermore, the school authority regularly arranges teacher meetings to discuss any infrastructural development issues.

Measures to adapt to waterlogged conditions are also taken by managers and administrators. School management committee members prepare plans to drain/elevate school fields, construct sand-packed roads for students, contact political leaders and local administration for support, and support boy and girl scouts for the improvement of roads. Improving school sanitation and the installation of deep tubewells (hand pumps) for drinking water are also focus areas for committee members, connecting to their organization of student rallies to raise awareness of the effects of various diseases such as chikungunya and dengue. Committee members also attempt to contact students during flood events, through mobile phones or personal house visits, to ensure their safety.

The state has become involved through Education administrators and has adopted various strategies in the past to mitigate the effects of flooding on academic activities. In order to track flood damage, in 2017, a list of damaged educational institutions was prepared in response to a particularly excessive amount of annual rainfall. Moving forward, the cleanliness of all educational institutions is emphasized in the immediate aftermath of any flooding event. Bleaching powder is supplied to clean the institutions quickly ensuring acceptable hygiene under an Emergency-in-Education-Fund. Administrators emphasize the importance of establishing new buildings, classroom expansion, construction of school boundary walls, and provision of new books to replace any that have been damaged. An "E-Monitoring" system is being developed so that the condition of schools in remote areas can be easily documented and closely monitored. Because schools are used as shelters during flood events, teachers are instructed to run make-up classes to compensate for loss of classes. Weak students are given extra care and teachers are encouraged to keep attendance rates as high as possible.

\section{STAKEHOLDERS' HOPES FOR PROGRESS}

During the interviews and FGDs, school stakeholders spoke about the progress that they hoped for that would enable the continuation of school education during and after prolonged flooding and waterlogging conditions. Participants emphasized that community participation is important to solve this problem, and here we look at potential progress in terms of a) physical assets, b) safety and health and c) broader development.

\section{Physical Assets}

Many participants in the study indicated that the key area that needed to be addressed was the quality and maintenance of physical assets in Dhaka schools and communities. Students spoke to the need for school playground levels to be raised - the aspiration to continue "normal" education during flooding and waterlogging was clear - while all stakeholders were concerned about ensuring a safe and healthy working environment, on elevated land with a good drainage system. To maintain a good environment, drains should be cleaned more regularly, and water bodies need to be kept free from being filled up. Participants broadly spoke to the need for classrooms and school plinths to be elevated and for improvement to be made to drainage, transportation, and road infrastructures.

\section{Safety and Health}

Participants discussed how transport could be better arranged by the schools during waterlogged conditions. Technology and information systems could be improved to ensure the continuity of education and safety of students during emergencies and drawn-out suboptimal conditions. Pure drinking water must be arranged for the students. Pedestrian footbridges are important in the school locality for the safety of the students. Continuous supply of electricity 
should be ensured. An innovative suggestion was to provide midday meals in the schools of flooded areas. School Managing Committees believed that the government should spend more on providing safe drinking water and were interested in obtaining financial support for students from individuals or NGOs. For the wellbeing of children, umbrellas and raincoats should be provided during periods of excessive rainfall and flooding, and disaster preparedness techniques should be taught.

\section{Broader Development}

Participants felt that City Corporations must play an active role to manage wastes, illegal land grabbing and filling, and informal construction that cause waterlogging. There is a possibility of recovering water bodies near the schools from illegal occupation, not only to improve the waterlogged conditions, but also to make the roads wider by freeing from encroachment. It was essential to improve the drainage system, and the Dhaka City Corporation and Water and Sewerage Authority (WASA) should take this issue seriously. Some participating teachers argued that the government and local authorities should take necessary steps to solve the structural issue of waterlogging, and also that the establishment of high-rise buildings might solve the shortage of classrooms. Pollution should be controlled and monitored in an effective way and waste treatment plants should be established.

Throughout all these hopes for progress runs the important hope for maintaining continuity in children's education. Parents that participated in the study emphasized that community participation is important to solve this problem, and on the need for awareness building programs arranged by the schools.

And the government is taking certain measures to ensure education continuity, such as mandating additional classes. This is something that needs to be properly monitored. Alongside this locally mandated advice, the Education Administration recommends counseling facilities for students and the integration of disaster preparedness into operations; this includes implementation of the Comprehensive School Safety Framework to ensure resilient school buildings.

\section{DISCUSSION}

The major stakeholders of the schools in Dhaka City experience severe waterlogging and resultant consequences on a regular basis, which are the major barriers for smooth continuity of school education in a significant number of schools in Dhaka. Students, teachers, and parents are directly affected due to waterlogging conditions. Students are the worst sufferers and face tremendous difficulties in successfully completing the syllabuses due to prolonged stagnation of water in and around schools, while their parents suffer as their children are not able to timely finish the syllabus and ultimately have poor examination results. School management committee is always in a havoc during prolonged waterlogging situation in preparing the students for certificate examinations. In case of failure to successfully accomplish annual syllabuses and to timely upgrade respective batch of students, the management committee has to be accountable to the higher authorities.

The study schools being located in the close vicinity of industries are highly exposed to chemicals. Chemical smoke emitting from the re-rolling industries seriously affect students' health. During wet months, liquid chemicals mixing with storm water inundates the school compound. Students experience knee-deep waterlogging mixed with hazardous wastewater disposed from the nearby industries when coming to the schools. Very often during waterlogged situations, students cannot attend classes timely and get affected due to water-borne diseases. In 2017, due to excessive rainfall, students' education has been hampered for several weeks. The present study shows that a significant number of students live in poor housing conditions. Due to waterlogging, they even suffer at home as their residences get inundated and they thus prefer going to school instead. Very often their books and uniforms get damaged in rainwater. Most of the students experience sickness during the flooded periods.

Despite the conditions, schoolteachers are pressured by education administrators to maintain satisfactory student attendance and graduation rates and are compelled to continue classroom activities whether students are present or not. Some schoolteachers elect to host make-up classes to give students a chance to compensate for lost time. In private primary schools, one of the major challenges of teachers is to maintain high examination scores 
from their students; this becomes difficult when attendance rates drop due to the risk associated with commuting to and from school during flood events. In order to remedy the situation, management committees attempt to maintain school safety on their own without the aid of education administrators. If student attendance drops below a certain threshold, the school may struggle to enroll more students in the future as its reputation begins to suffer. Finally, the administrative authorities (both MoE and MoPME) are responsible for ensuring the continuity of education in schools, although these institutions have yet to prepare a framework to guide the implementation of comprehensive school safety initiatives in Dhaka.

\section{CONCLUSION}

Dhaka City hosts over 400 schools, many of which are located in the peri-urban areas. A major concentration of people also exists in these areas, or example- Jatrabari, Kamrangirchar, Shayampur, Demra, Madartek, Goran (among many such localities) where this study was conducted. A large number of industries of different scales have been operating in these areas that were mostly set up in an unplanned and haphazard manner. Only a tiny fraction $(10 \%)$ of the schools in Dhaka is well-constructed and relatively safe from hazards such as floods and earthquakes.

The students, parents, teachers, school governing bodies and the government agencies (Ministry of Education and Ministry of Primary and Mass Education) are the five major stakeholders relating to the school education system. The students are usually the worst victims due to disasters in Dhaka particularly in the regular occurrence of waterlogging events. They face a number of challenges in attending schools particularly in the wet season (June-October) every year. The students in the peri-urban areas are mostly from poor socio-economic conditions and live in sub-standard housing including slums. Due to heavy rainfall, the slums and squatters are usually inundated, and the students experience severe problems of staying at home, continuing their education, and attending school regularly. Sometimes their parents do not have any work during waterlogged conditions and ultimately the students' education is highly disrupted.
The most important initiatives for the other four groups of school stakeholders would be to ensure smooth and efficient continuation of academic activities of the students. In order to achieve the goal of effective education in schools, the CSS (Comprehensive School Safety) guidelines for ensuring safer and resilient buildings has to be implemented so that the students during and after disasters can smoothly continue academic activities. In addition, regular safety drills on floods and waterlogging, fires, earthquakes and other hazards, continuous awareness building through seminars and public consultations are necessary to develop resilience of schools and allow educational continuity.

Acknowledgement: The paper is based on the research project entitled "Critical Factors for Post-Disaster Educational Continuity in Urban Flood Impacts in South and Southeast Asia" commissioned by Save the Children and led by the University of Newcastle, Australia in partnership with the University of Dhaka, Bangladesh for the Bangladesh component of the project.

\section{REFERENCES}

ACAPS (2018). Bangladesh Flooding Situation-Disaster Summary Sheet (20 May 2018). Dhaka: Assessment Capacities Project (ACAPS).

ADB and WB (2005) 2004 Floods in Bangladesh: Damage and Needs Assessment and Proposed Recovery Program (report). Manila: Asian Development Bank (ADB) and Washington D.C.: World Bank (WB).

Ahmad, Q.K., Chowdhury, A.K. A., Imam, S.H. and Sarker, M. (2000). Perspectives on Flood 1998. Dhaka: University Press Limited, Dhaka.

Ahmed, I. (2014). Factors in Building Resilience in Urban Slums of Dhaka, Bangladesh. Procedia Economics and Finance, 18, 745-753.

Ahsan, R.M. and Khatun, H. (eds.) (2004). Disaster and Silent Gender: Contemporary Studies in Geography. Dhaka: Bangladesh Geographical Studies (BGS), University of Dhaka, Dhaka.

Alam, K., Siddiqi, M.S., Hossain, K., Rashed, A.A., Haque, M.A. and Kabir, S. (2011). Disaster Resilient Primary Education in Bangladesh: Problems, Priorities and Actions for Disaster Risk Management in Primary Education (report). Illford, UK: Think Ahead Consulting Limited, Illford, UK. BANBEIS (2016). Bangladesh Education Statistics 2015. Dhaka: Bangladesh Bureau of Educational Information and Statistics (BANBEIS). 
Dewan, A.M. and Corner, R. (ed.) (2014). Dhaka Megacity: Geospatial Perspectives on Urbanization, Environment and Health. Dordrecht, Germany: Springer, Dordrecht.

Dewan, A.M., Kabir, M.H., Islam, M.M., Kumamoto, T. and Nishigaki, M. (2007). Delineating Flood Risks in Greater Dhaka of Bangladesh Using Geoinformatics. Georisk, 1(4), 190-201.

Dewan, A.M., Kabir, M.H., Nahar K. and Rahman, Z. (2012). Urbanization and Environmental Degradation in Dhaka Metropolitan Area of Bangladesh. International Journal of Environment and Sustainable Development, 11 (2): 118-147.

ECHO (2010). School Safety towards Building Disaster Resilient Schools in Bangladesh. European Commission for Humanitarian Office (ECHO), Newsletter 4, August 2010.

GADRRRES (2017). The Comprehensive School Safety Framework. Global Alliance for Disaster Risk Reduction \& Resilience in the Education Sector (GADRRRES). Available from: https://www. preventionweb.net/files/ 55548_css framework 2017. pdf (accessed 15 December 2020).

Islam, N. (2005). Natural Hazards in Bangladesh: Studies in Perception, Impact and Coping Strategies. Dhaka: Disaster Research Training and Management Centre (DRTMC), University of Dhaka.

World VisionLim, M.B., Co, R., Riesmasari, C., Chanphearum, K., Pimmata, O. and Berandi, R. (uUndated). Comprehensive School Safety Practices in Asia, Development of Cases from Cambodia, Indonesia and Lao PDR (report) supported by the ASEAN Safe School Initiative, World Vision International. Bangkok: World Vision International - East Asia.

MoDMR (2016). National Plan for Disaster Management 2016-2020. Dhaka: Ministry of Disaster Management and Relief (MoDMR), Government of Bangladesh.
MoDMR (2019). Standing Orders on Disaster. Dhaka: Ministry of Disaster Management and Relief (MoDMR), Government of Bangladesh.

MoE (2010). National Education Policy 2010. Dhaka: Ministry of Education (MoE), Government of the People's Republic of Bangladesh, Dhaka, Government of Bangladesh..

Parvin, G.A., Ahsan, S.M.A. and Shaw, R. (2013)., Urban Risk Reduction Approaches in Bangladesh in R. Shaw, F. Mallick and A. Islam (eds.) Disaster Risk Reduction Approaches in Bangladesh. Tokyo: Springer, Tokyo.

Rahman, A., Shaw, R., Surjan, A. and Parvin, G.A. (2016), Urban Disasters and Approaches to Resilience in $\mathrm{R}$. Shaw, A. Rahman, A. Surjan, G.A. Parvin (eds.), Urban Disasters and Resilience in Asia. Amsterdam: Elsevier Inc, Amsterdam, 1-19.

NIRAPAD (2017). Bangladesh: Flash Flood Situation (19 April 2017). Dhaka: NIRAPAD.

Save the Children (2017). Bangladesh Education Safe from Disasters Strategic Plan 2016-2018, Save the Children Bangladesh, Dhaka.

Shaw, R., Mallick, F.H. and Islam, A. (2013). Disaster Risk Reduction Approaches in Bangladesh. Tokyo, Springer, Tokyo.

UNICEF (2010). Baseline Assessment Report for a Model Community School, Dhaka: United Nations Children's Fund (UNICEF), submitted to the Ministry of Education, Government of the People's Republic of Bangladesh, Dhaka.

von Meding, J., Ahmed, I., Howard, A., Forino, G., Pal, I., Kabir, H., Dao, H. and Thai, H. (2018). Critical Factors for Post-Disaster Educational Continuity in Urban Floods in South and Southeast Asia. Singapore: Save the Children Asia Regional Office. 